\title{
Erratum to: Paying Out One or All Trials: a Behavioral Economic Evaluation of Payment Methods in a Prototypical Risky Decision Study
}

\author{
Barbara Schmidt ${ }^{1}$. Johannes Hewig ${ }^{1}$
}

Published online: 1 April 2016

(C) Association for Behavior Analysis International 2016

\section{Erratum to: Psychol Rec}

DOI 10.1007/s40732-014-0112-1

In Figure 2 of the published article, the effect size for the behavioral effect is $d=.31$ (left side of the figure), whereas in the text, it is $d=.5$. The right size is $d=.5$. The corrected Figure 2 appears below.

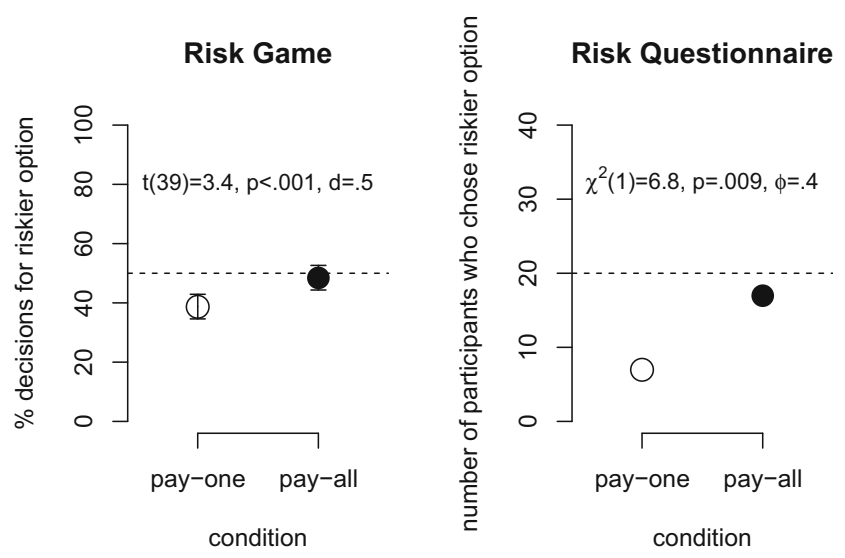

The online version of the original article can be found at $\mathrm{http}: / / \mathrm{dx} . \mathrm{doi}$. org/10.1007/s40732-014-0112-1.

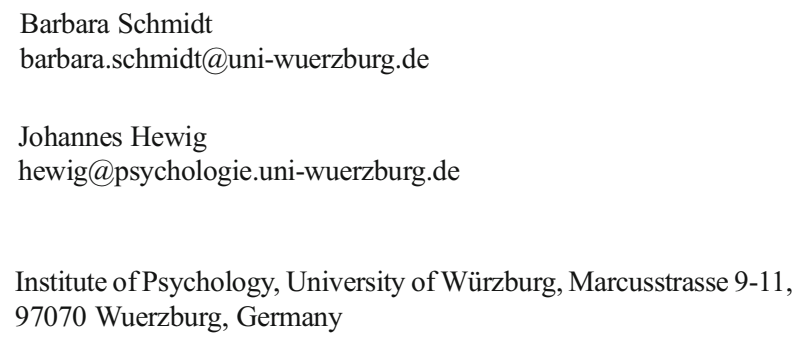

